\title{
Pembuatan Prothesa Telinga dengan Metode Pencetakan Tiga Lapis
}

\author{
Helmi Fathurrahman, Titik Ismiyati, Suparyono Saleh dan Haryo Mustiko Dipoyono \\ Program Studi Prortodonsia, PPDGS, Fakultas Kedokteran Gigi, Universitas Gadjah Mada \\ JI Denta No 1 Sekip Utara, Yogyakarta, Indonesia; e-mail: fathurhanafie@gmail.com
}

\begin{abstract}
ABSTRAK
Defek telinga unilateral ataupun bilateral dapat disebabkan oleh berbagai faktor, diantaranya trauma, kelainan pertumbuhan, atau prosedur pengangkatan kanker. Kondisi ini akan mempengaruhi psikologis pasien karena telinga merupakan organ vital yang membentuk estetika wajah. Salah satu perawatan rehabilitasi pada defek telinga adalah dengan pembuatan protesa telinga. Tahapan penting dari pembuatan protesa telinga adalah mendapatkan cetakan yang akurat untuk membuat pola malam. Teknik pencetakan dalam pembuatan prothesa telinga diantaranya metode reversible hydrocolloid dengan sendok cetak malam, irreversible hydrocolloid dengan sendok cetak kaku dan metode pencetakan tiga lapis. Keunggulan teknik pencetakan tiga lapis adalah mudah di lakukan dan akurasi hasil pencetakan yang baik. Tujuan laporan kasus ini adalah mengaplikasikan teknik pencetakan tiga lapis dalam pembuatan prothesa telinga. Perawatan dilakukan pada seorang pria berusia 14 tahun yang mengalami defek kongenital telinga dextra (unilateral). Langkah pertama dalam pembuatan prothesa yaitu pencetakan telinga normal dan defek, dilanjutkan pembuatan pola malam dan basis protesa, kemudian tahap try in pola malam, processing silikon, dan insersi. Prosedur pencetakan telinga dengan teknik tiga lapis yaitu mengaplikasikan irreversible hidrocolloid pada regio post aurale (lapisan pertama), regio pra aurale, permukaan internal, (lapisan kedua), dan permukaan luar telinga (lapisan ketiga). Hasil pencetakan telinga dengan teknik tiga lapis adalah tiga lapisan irreversible hidrocolloid yang solid dan mudah untuk dipisahkan sehingga menjamin akurasi hasil pengecoran. Kesimpulan laporan kasus ini adalah teknik pencetakan tiga lapis dapat diaplikasikan dalam pembuatan prothesa telinga.
\end{abstract}

Maj Ked Gi. Juni 2014; 21(1):78-83

Kata kunci: Prothesa telinga, teknik pencetakan tiga lapis, akurasi, pola malam.

ABSTRACTS: Triple Layer Impression Method For Auricular Prosthesis. An unilateral or bilateral auricular defect can be caused by several factors including trauma, congenital malformation or surgical removal of neoplasm. These condition will affect patient psycologic because ear is a vital part of facial aesthetic. One of rehabilitation care of auricular defect is an auricular prosthesis. Important stage of making auricular prosthesis is to obtain accurate impression to make wax pattern. Impression technique including method of reversible hydrocolloid with wax collar, irreversible hydrocolloid with rigid tray and triple layer impression method. The excellence of the triple layer impression technique are easy to do and accuracy of good impression result. The aim of this case report is to apply triple layer impression method in the making of auricular prosthesis. The treatment was done in 14 years old male patient with chief compain of congenitally defect of external dextra ear. First step of making auricular prosthesis is making an impression of defect area and opposite ear, making prothesa basis and wax pattern, try in the wax pattern, sillicone processing, and insertion the prothesa. Triple layer impression method was done in three step, first the impression material was injected to post aurale region (first layer), than injected to internal surface of ear (second layer). Subsequently, the third layer of impression material was partially filled into the tray and external surface of ear. The result of triple layer impression method in the making of auricular prosthesis is triple layer of solid irreversible hydrocolloid but separatable completly. Conclusion of this case report is the triple layer impression method is suitable for making an auricular prosthesis.

Maj Ked Gi. Juni 2014; 21(1):78-83

Keywords : auricular prosthesis, triple layer impression method, accuration, wax pattern.

\section{PENDAHULUAN}

Defek telinga unilateral ataupun bilateral dapat disebabkan oleh berbagai faktor, diantaranya trauma, kelainan pertumbuhan, atau prosedur pengangkatan kanker. Kondisi ini akan mempengaruhi psikologis pasien karena telinga merupakan organ vital yang membentuk estetika wajah. ${ }^{1}$
Perawatan rehabilitasi pada defek telinga ini dapat dilakukan dengan metode bedah dan non bedah. Metode bedah dengan pemanfaatan jaringan autogenus merupakan pilihan perawatan yang paling baik. Kekurangan perawatan bedah yaitu tidak dapat dilakukan pada pasien yang memiliki kontraindikasi bedah, beresiko tinggi, membutuhkan waktu penyembuhan, dapat ditolak 
oleh tubuh, dan relatif mahal. Alternatif perawatan yang tidak dapat dilakukan dengan metode bedah adalah dengan pembuatan prothesa telinga. ${ }^{2}$

Pembuatan prothesa telinga membutuhkan ketepatan orientasi dan detail bentuk yang baik, terutama pada pasien dengan defek unilateral, sehingga kesulitan utama dalam pembuatan protesa telinga adalah menghasilkan cetakan yang akurat untuk membuat pola malam ${ }^{3}$. Keakuratan hasil cetakan ditentukan oleh penggunaan jenis bahan cetak dan teknik pencetakan. Bahan cetak yang biasa digunakan dalam pembuatan prothesa telinga diantaranya reversible hydrocolloid, irreversible hydrocolloid, dan elastomer'. Teknik pencetakan yang dapat diaplikasikan dalam pembuatan prothesa telinga diantaranya metode dua cetakan dengan bahan cetak plaster, reversible hydrocolloid dengan sendok cetak malam, irreversible hydrocolloid dengan sendok cetak kaku dan metode pencetakan tiga lapis. ${ }^{5}$

Metode pencetakan tiga lapis menggunakan bahan cetak irreversible hydrocolloid yang diaplikasikan dalam tiga tahapan berbeda sehingga meningkatkan keakuratan hasil cetakan. Keunggulan teknik pencetakan tiga lapis adalah mudah dilakukan dan akurasi hasil pencetakan yang baik. Tujuan laporan kasus ini adalah mengaplikasikan teknik pencetakan tiga lapis dalam pembuatan prothesa telinga. Pasien dalam laporan kasus ini telah menyetujui untuk dipublikasikan kasusnya untuk kepentingan ilmu pengetahuan.

\section{METODE}

Pasien laki-laki berusia 14 tahun datang ke klinik Prostodonsia RSGM Prof. Soedomo FKG UGM karena ingin dibuatkan prothesa telinga. Pasien merasa tidak percaya diri karena daun telinga kanan rusak sejak lahir. Dua tahun yang lalu pasien pernah menjalani operasi bedah plastis untuk membentuk daun telinga kanan, namun prosedur tersebut tidak berhasil karena pertumbuhan jaringan keloid dan penolakan oleh tubuh (Gambar 1). Dokter yang menangani akhirnya menyarankan untuk dibuatkan prothesa telinga.
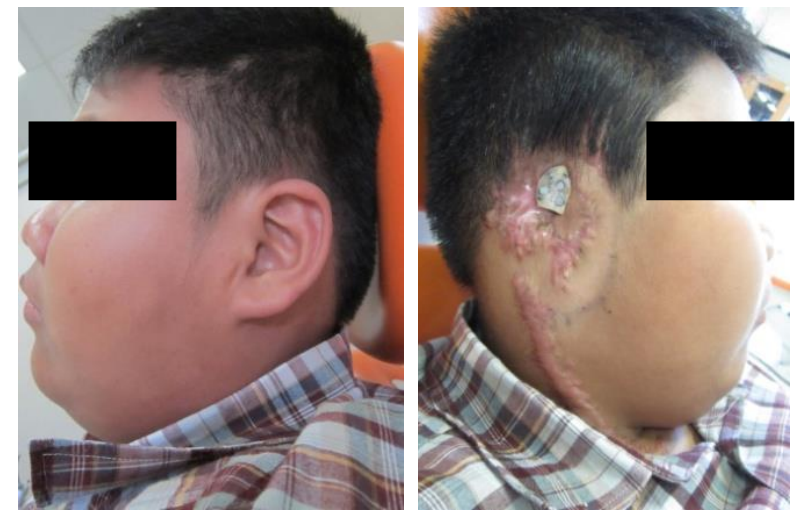

Gambar 1. Kondisi telinga dekstra dan sinistra

Keadaan umum pasien baik dan tidak memiliki riwayat penyakit sistemik. Pemeriksaan klinis ekstra oral menunjukkan adanya defek luas telinga dekstra yang disertai dengan pertumbuhan jaringan parut disekelilingnya. Meatus akustikus eksternus tertutup oleh plat akrilik berdiameter 4 cm yang di tanam subepitel dan dikaitkan dengan skrup pada tulang temporalis. Tidak terdapat tanda peradangan pada daerah defek. Telinga sinistra tidak mengalami kalainan.

Berdasarkan kondisi telinga pasien tersebut maka direncanakan pembuatan protesa telinga dekstra kaitan magnet dengan metode pencetakan tiga lapis. Tahapan pembuatan prothesa telinga pada kasus ini adalah : Pencetakan daerah defek dan telinga normal (sinistra), Pembuatan basis prothesa dari resin akrilik heat cure, Pencetakan telinga dekstra dari donor yang memiliki dimensi dan anatomis yang serupa (Gambar 3-6), Pembuatan model malam telinga dari hasil pencetakan telinga donor (Gambar 8), Pemasangan keeper pada resin akrilik yang tertanam di daerah defek (Gambar 10), Pemasangan magnet pada basis prothesa (Gambar 10), Try in model malam (Gambar 11), Penentuan warna telinga (Gambar 12), Processing prothesa telinga dengan bahan silicone dan Insersi (Gambar 13)

Pencetakan telinga normal (sinistra) dan telinga donor, dilakukan menggunakan teknik tiga lapis dengan bahan irreversible hydrocolloid. Sebelum pencetakan dimulai meatus akustikus eksternus ditutup kapas yang diikat dengan 
benang. Pasien diposisikan supine di kursi dental dengan wajah menghadap ke samping sehingga telinga yang hendak dicetak menghadap ke atas, kemudian sendok cetak invidual dicobakan pada area pencetakan (Gambar 2).

Bahan cetak irreversible hydrocolloid dimanipulasi sesuai petunjuk pabrik dan di masukkan ke dalam syringe berkapasitas $50 \mathrm{ml}$. Sebagai lapisan pertama bahan cetak di injeksikan pada daerah post aurale mulai dari titik pra, poa, dan meluas hingga batas infeoanterior lobus telinga (Gambar 3). Setelah lapisan pertama mengalami initial setting lapisan kedua diinjeksikan pada daerah permukaan dalam telinga mulai dari tragus, helix, antihelix, fosa triangular, meatus akustikus eksternus, konka, tragus, anti tragus, lobus hingga permukaan luar telinga (Gambar 4). Selanjutnya lapisan ketiga diaplikasikan di sekeliling telinga hingga memenuhi sendok cetak individual (Gambar 5). Setelah lapisan ketiga mengeras bagian inferior cetakan diangkat perlahan hingga cetakan terlepas dari telinga (Gambar 6).

Bahan pengisi cetakan disesuaikan dengan tujuan dari pencetakan, pada pembuatan model studi (pencetakan telinga sinistra pasien) hasil cetakan diisi dengan dental stone tipe IV (Gambar 7), sedangkan pada pembuatan model malam (pencetakan telinga dekstra donor) hasil cetakan diisi dengan malam base plate yang di cairkan (Gambar 8).

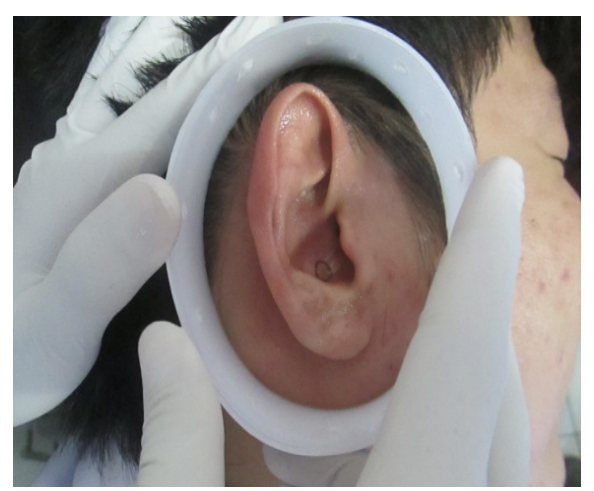

Gambar 2. Try in sendok cetak individual

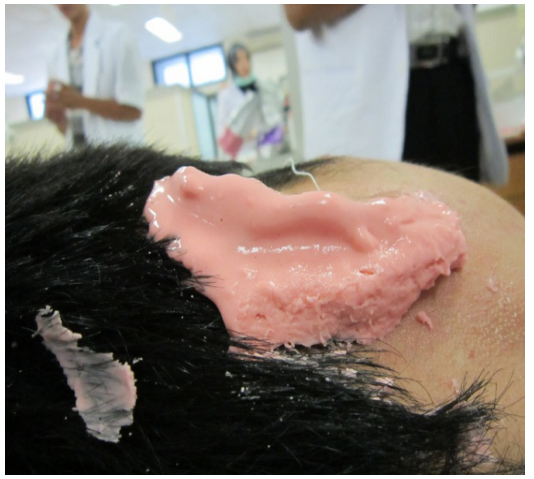

Gambar 3. Aplikasi bahan cetak pada daerah post aurale (lapisan pertama)

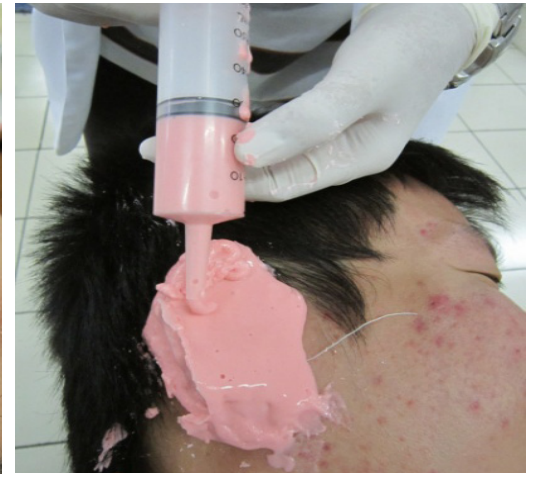

Gambar 4. Aplikasi bahan cetak pada permukaan dalam telinga (lapisan kedua)

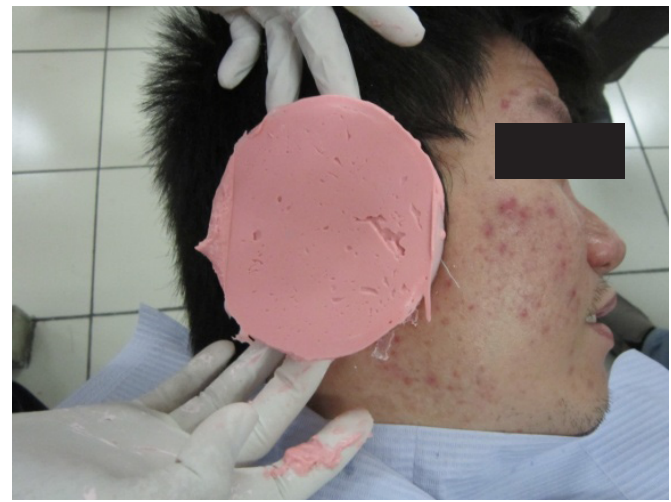

Gambar 5. Aplikasi bahan cetak di sekeliling telinga (lapisan ketiga)

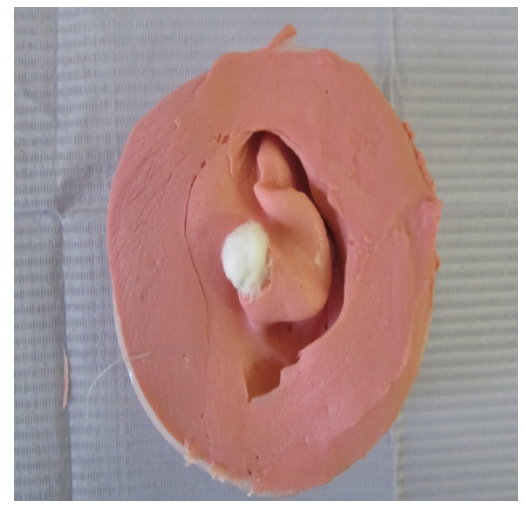

Gambar 6. Hasil pencetakan telinga dengan metode pencetakan tiga lapis 


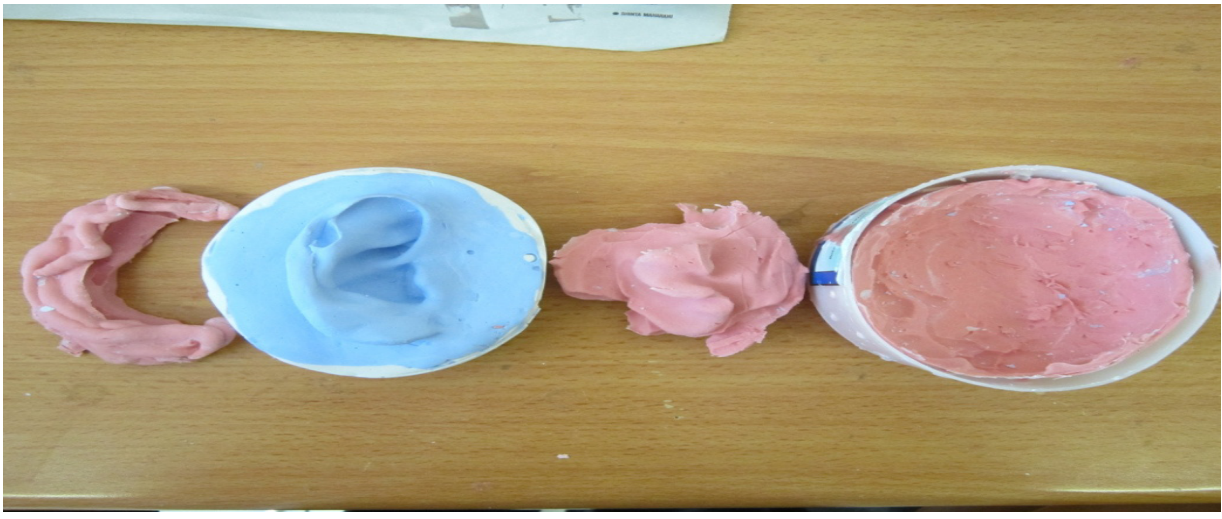

Gambar 7.Hasil pengisian cetakan dengan dental stone

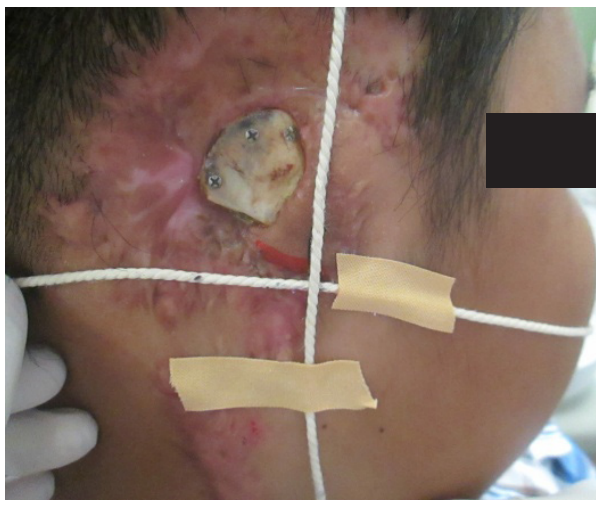

Gambar 9. Garis orientasi penempatan prothesa

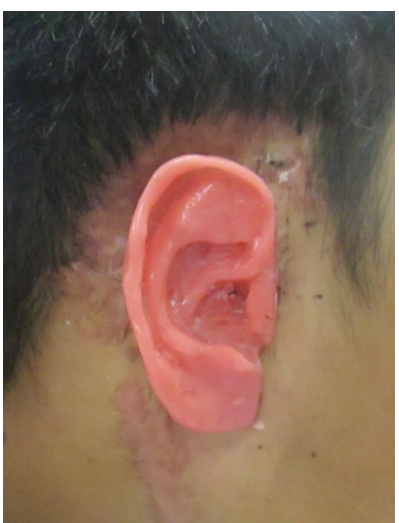

Gambar 11. Try in pola malam pada pasien

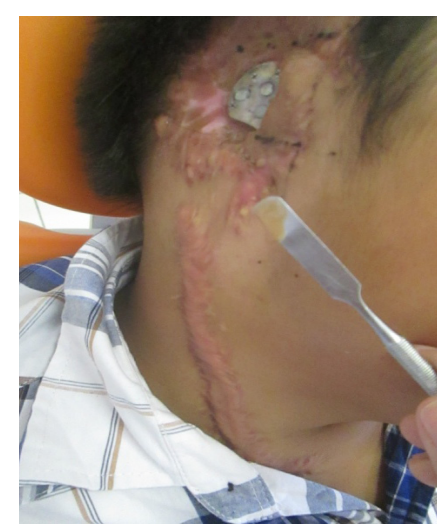

Gambar 12. Penentuan warna

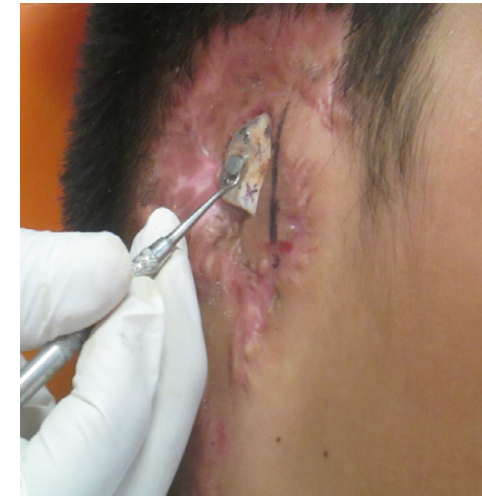

Gambar 10. Pemasangan keeper dan magnet basis prothesa

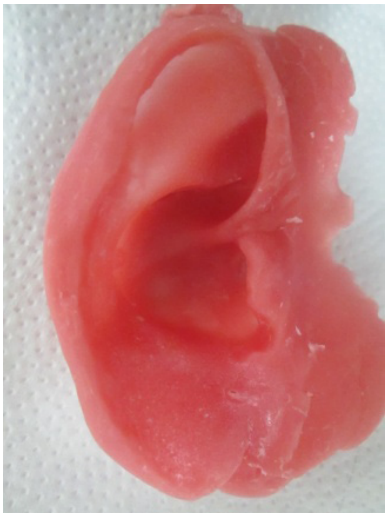

Gambar 8. Hasil pengisian cetakan dengan base plate wax

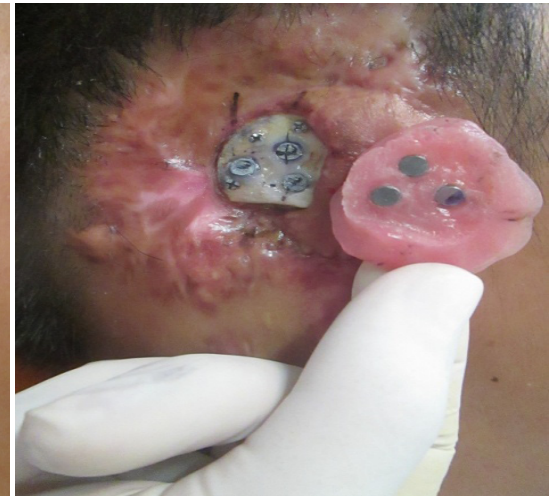


proses pelepasan melewati daerah undercut. Daerah undercut pada pencetakan telinga terdapat pada area post aurale dan helix.

Teknik pencetakan tiga lapis menghasilkan tiga lapisan irreversible hidrocolloid yang solid dan mudah untuk dipisahkan sehingga menjamin akurasi hasil pengecoran. Hasil yang sama dibuktikan oleh Mohamed dkk., ${ }^{5}$ yang telah membandingkan teknik pencetakan tiga lapis dengan teknik pencetakan konvensional dalam membuat protesa telinga.

Karakteristik utama dari teknik pencetakan tiga lapis adalah pembuatan tiga lapisan dilakukan secara bertahap setelah lapisan pertama mencapai fase initial setting sehingga aplikasi bahan cetak selanjutnya tidak menimbulkan distorsi bentuk telinga. Teknik pencetakan konvensional menggunakan satu lapisan bahan cetak yang dituang dalam waktu yang sama, akibatnya terjadi distorsi bentuk telinga akibat pembebanan bahan cetak. Menurut Mohamed dkk., ${ }^{5}$ distorsi hasil cetakan dengan teknik konvensional terjadi pada regio helix dan antihelix.

Pada kasus ini untuk mempermudah pembuatan prothesa teknik pencetakan tiga tahap dilakukan untuk dua tujuan, pembuatan model studi dan pola malam. Perbedaannya terdapat pada bahan pengisi hasil cetakan, pada pembuatan model studi hasil cetakan diisi dengan dental stone tipe IV, sedangkan pada pembuatan model malam hasil cetakan diisi dengan malam base plate yang di cairkan. Teknik pencetakan ini dapat digunakan untuk membuat model malam karena setelah pengisian cetakan bahan cetak dapat dilepaskan terpisah antar bagian, sehingga tidak merusak pola malam (Gambar 10). Nelogi dkk. ${ }^{2}$, menyebutkan bahwa pola malam dapat dibuat dengan cara mencetak telinga donor yang memiliki dimensi yang sama dengan telinga pasien, kemudian mengisi hasil cetakan tersebut dengan malam base plate. Hasil penelitian yang dilakkan oleh Liacouras dkk., ${ }^{7}$ menyatakan bahwa terdapat teknik lain yang lebih akurat dalam membuat cetakan dan pola malam protesa telinga. Teknik tersebut menggunakan computer tomography yang dilengkapi dengan sistem 3-D photography, namun membutuhkan biaya yang lebih besar dari teknik pencetakan tiga lapis.

Kesulitan teknik pencetakan tiga lapis pada kasus ini adalah mengaplikasikan bahan cetak irreversible hidrocolloid pada permukaan dalam telinga karena bentuk anatomis yang terdiri dari banyak lekukan dan udercut. Solusi kondisi ini adalah aplikasi bahan cetak menggunakan spuit injeksi atau mengganti bahan cetak dengan elastomer light viscosity. ${ }^{5}$ Penggunaan bahan cetak elastomer membutuhkan biaya besar, sehingga pemanfaatan spuit injeksi menjadi pilihan solusi pada kasus ini.

\section{KESIMPULAN}

Kesimpulan laporan kasus ini adalah teknik pencetakan tiga lapis dapat diaplikasikan dalam pembuatan prothesa telinga.

\section{DAFTAR PUSTAKA}

1. Chung W, Robin C, Siu S, Adam C, Chu C, Frederick S, Chow WT. Magnet retained auricular prosthesis with an implant supported composite bar a clinical report.J Prosthet Dent. 2003; 89446-449

2. Nelogi SY, Chandrashekhar NH, Porwal A. Modified technique for retaining silicone auricular prosthesis a case report. Eur $\mathrm{J}$ Prosthodont Rest Dent. 2011; 1962-66

3. Thotapalli S. Fabrication of mirror image prosthetic ears-a short review. Anaplastology. 2013;2120

4. Mathews MF, Sutton AJ, Smith RM. The auricular impression an alternate technique, $\mathrm{J}$ Prosthodont. 2000; 9(2):106-109

5. Mohamed K, Mani UM, Seenivasan MK, Vaidyanathan AK. Comparison of two impression techniques for auricular prosthesis: pilot study. JRRD.2013;501079-1088

6. Thomas KF. Impression material and techniques. In; The art of clinical anaplastology S Thomas, England; 2006; 29 
7. Liacouras P, Garnes J, Roman M, Petrich A, ' Grant GT. Design and manufacturing an auricular prosthesis using computed tomography, 3-dimensional photographic imaging, and additive manufacturing: clinical report, J Prosthet Dent. 2011;10578-82
8. Shah DN, Chauhan, CJ. Auricular prosthesisthe overlooked skill in prosthodontics. The Journal of Ahmedabad Dental College and Hospital.2010;1(1)37-40 